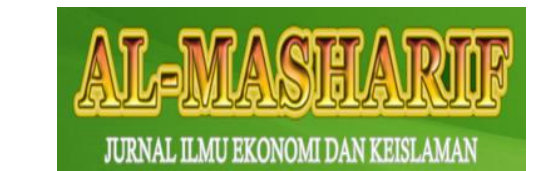

Al-Masharif: Jurnal Ilmu Ekonomi dan Keislaman

Volume 6 Nomor 1 Ed. Januari-Juni 2018 : hal. 130-144

p-ISSN: 2356-4628 e-ISSN : 2579-8650

\title{
PENGARUH PERTUMBUHAN EKONOMI, REALISASI \\ PENGELUARANPENDIDIKAN, DAN REALISASI \\ PENGELUARANKESEHATAN \\ TERHADAP INDEKS PEMBANGUNAN MANUSIA DALAM PANDANGAN ISLAM DI PROVINSI SUMATERA UTARA
}

\author{
Zulaika Matondang \\ IAIN Padangsidimpuan \\ Jalan T. Rizal Nurdin Km. 4,5 Sihitang, Padangsidimpuan \\ Email : zulaikamatondang83@gmail.com
}

\begin{abstract}
Abstrak,
Penelitian ini dilakukan dengan tujuan untuk mengetahui pengaruh pertumbuhan ekonomi, realisasi pengeluaran pendidikan, realisasi pengeluaran kesehatan terhadap indeks pembangunan manusia di provinsi Sumatera Utara. Data yang diolah dalam penelitian ini adalah data sekunder yang diperoleh melalui data yang dipublikasi oleh Badan Pusat Statistik. Pertumbuhan ekonomi, realisasi pengeluaran pendidikan dan realisasi pengeluaran kesehatan berpengaruh sebesar 86,5 persen sedangkan sisanya sebesar 13,5 persen dipengaruhi oleh variabel lain diluar penelitian ini. Pertumbuhan ekonomi berpengaruh terhadap indeks pembangunan manusia dengan pembuktian hasil $t$ hitung lebih besar nilainya daripada $t$ tabel yaitu 4,793 $>2,119$, Realisasi pengeluaran pendidikan berpengaruh terhadap indeks pembangunan manusia dengan pembuktian hasil $\mathrm{t}$ hitung lebih besar nilainya daripada $t$ tabel yaitu 3,239 > 2,119 dan Realisasi pengeluaran kesehatan berpengaruh terhadap indeks pembangunan manusia dengan pembuktian hasil -t hitung lebih kecil nilainya daripada -t tabel yaitu $-2,678<-2,119$. Dan secara simultan pertumbuhan ekonomi, realisasi pengeluaran pendidikan dan realisasi pengeluaran kesehatan berpengaruh terhadap indeks pembangunan manusia di provinsi Sumatera Utara yang dibuktikan dari nilai F hitung lebih besar daripada F tabel yaitu 34,130 > 3,10.
\end{abstract}

Kata Kunci :Indeks Pembangunan Manusia, Pertumbuhan Ekonomi, Realisasi Pengeluaran Pendidikan, dan Realisasi Pengeluaran Kesehatan.

\begin{abstract}
,
This study was conducted with the aim to determine the effect of economic growth, realization of education expenditure, realization of health expenditure on the human development index in the province of North Sumatra. The data processed in this study is secondary data obtained through data published by the Central Bureau of Statistics. Economic growth, realization of education expenditure and realization of influential health expenditure by 86.5 percent while the remaining 13.5 percent is influenced by other variables outside this study. Economic growth affects the human development index by proving the results of $t$ count greater than $t$ table that is $4.793>2.119$, realization of education expenditure affects the human development index by proving the results of $t$ count greater than $t$ table is 3.239> 2.119 and realization of health expenditure have an effect on the human development index by proving that the results of $t$-count are smaller than the $-t$ table, which is $-2.687<-2.119$. And simultaneously economic growth, realization of education expenditure and realization of health expenditures affect the human development index in the province of North Sumatra as evidenced from the calculated $F$ value is greater than F table is $34.130>3.10$
\end{abstract}

Keywords: Human Development Index, Economic Growth, Realization of Education Expenditures, and Realization of Health Expenditures. 
PENGARUH PERTUMBUHAN EKONOMI, REALISASI PENGELUARAN PENDIDIKAN, DAN REALISASI PENGELUARANKESEHATAN TERHADAP INDEKS PEMBANGUNAN MANUSIA DALAM PANDANGAN ISLAM DI PROVINSI SUMATERA UTARA

\section{PENDAHULUAN}

Zulaika Matondang

Pada awalnya, indikator pembangunan ekonomi suatu wilayah ditentukan dari pendapatan per kapita wilayah tersebut dan menjadi perdebatan dikalangan para ekonom. Hal ini terjadi karena pendapatan per kapita suatu wilayah yang tinggi belum tentu mampu menentukan indikator-indikator yang ada dalam perekonomian juga tumbuh dengan baik. Sehingga pendapatan per kapita sebagai indikator pembangunan telah digugat oleh kalangan ekonomi maupun non ekonomi yang melihat ketidakakuratan indikator tersebut, sehingga memunculkan beberapa indikator baru yang terfokus pada pembangunan manusia (Setiawan dan Hakim, 2013).

Pembangunan manusia sangat penting dalam perekonomian, karena manusia yang dalam hal ini adalah penduduk yang akan menjalankan dan sebagai penggerak perekonomian suatu wilayah. Dengan kata lain, penduduklah input penentu berkembangnya atau tumbuhnya perekonomian suatu wilayah dan penduduk jugalah output yang menggambarkan pembangunan wilayah tersebut. Pembangunan yang dilakukan diharapkan dapat meningkatkan kualitas kehidupan agar tercapainya masyarakat yang makmur dan sejahtera. Semakin baik kualitas penduduk suatu wilayah, maka pembangunan wilayah tersebut pun semakin baik sehingga pertumbuhan ekonomi wilayah tersebut mengalami peningkatan, bukan hanya dalam angka akan tetapi dapat dilihat juga dari segi kualitas penduduknya. Untuk mengukur keberhasilan pembangunan salah satu indikator yang bisa digunakan dengan melihat indeks pembangunan manusia.

Indeks pembangunan manusia merupakan salah satu untuk mengukur taraf kualitas fisik dan non fisik penduduk. Kualitas fisik tercermin dari angka harapan hidup sedangkan kualitas non fisik (intelektualitas) melalui lamanya rata-rata penduduk bersekolah dan angka melek huruf dan mempertimbangkan kemampuan ekonomi masyarakat yang tercermin dari nilai purcashing power parity (ppp) index (Andaiyani, 2012). Indeks pembangunan manusia memiliki tiga indikator yaitu angka harapan hidup untuk menilai tingkat kesehatannya, angka melek huruf dan rata-rata lama sekolah untuk menilai tingkat pendidikannya dan kemampuan daya beli untuk mengukur kemampuan pendapatannya. Indeks pembangunan manusia di provinsi Sumatera Utara dapat dilihat dari gambar berikut.

\section{Gambar 1}

Indeks Pembangunan Manusia di Provinsi Sumatera Utara

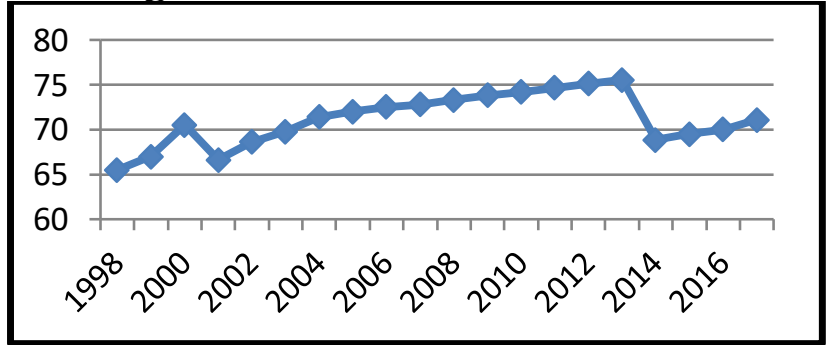

Provinsi Sumatera Utara adalah provinsi dengan jumlah masyarakat yang beragama Islam sebanyak 8.579.830 jiwa atau sebesar 66,089 persen dari seluruh jumlah penduduk di 
provinsi Sumatera Utara. Di dalam ajaran Islam juga menganjurkan agar memperhatikan pendidikan, Islam sangat mementingkan pendidikan dan ilmu pengetahuan, bahkan dianjurkan kepada pemeluknya agar mencari ilmu pengetahuan kapan dan dimana pun, karena manusia merupakan khalifah di muka bumi, dan yang membedakan derajat di antara manusia adalah ilmu yang dimilikinya seperti yang termuat di dalam Al-Qur'an surah AlMujadalah ayat 11 yang berbunyi :

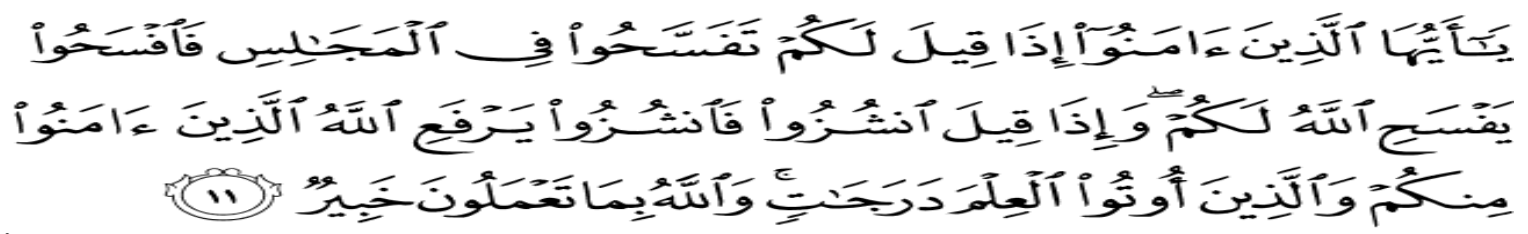

Artinya :

Hai orang-orang yang beriman apabila dikatakan kepadamu :"Berlapang-lapanglah dalam majlis", maka lapangkanlah niscaya Allah akan member kelapangan untukmu. Dan apabila dikatakan : "Berdirilah kamu”, maka berdirilah, niscaya Allah akan meninggikan orang-orang yang beriman diantaramu dan orang-orang yang diberi ilmu pengetahuan beberapa derajat. Dan Allah Maha Mengetahui apa yang kamu kerjakan.

Pendidikan dan kesehatan merupakan tujuan pembangunan yang mendasar, dimana kesehatan merupakan inti dari kesejahteraan dan pendidikan adalah hal yang pokok untuk menggapai kehidupan yang memuaskan dan berharga dan keduanya adalah hal yang fundamental untuk membentuk kemampuan manusia yang lebih luas yang berada pada inti makna pembangunan (Todaro, 2006). Pendidikan dan kesehatan merupakan modal dasar yang harus dimiliki masyarakatnya untuk melihat indeks pembangunan manusianya. Modal manusia melalui pendidikan akan dapat menambah produktivitas penduduk, dengan produktivitas yang tinggi akan meningkatkan pendapatan per kapita suatu wilayah yang justru akan meningkatkan pertumbuhan ekonomi di wilayah tersebut. Berikut laju pertumbuhan ekonomi di provinsi Sumatera Utara.

Gambar 2

Laju pertumbuhan ekonomi di Provinsi Sumatera Utara

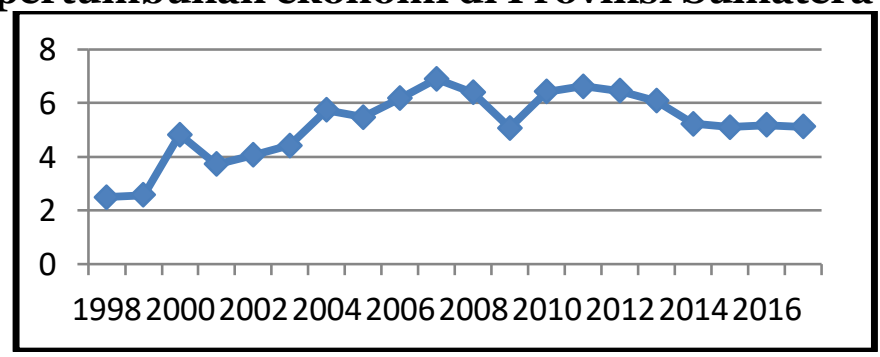

Pertumbuhan ekonomi yang baik akan mendorong peningkatan di bidang pendidikan dan kesehatan, sehingga dapat meningkatkan indeks pembangunan manusia melalui pengeluaran belanja pemerintah untuk memenuhi kebutuhan pembangunan dalam rangka meningkatkan kesejahteraan masyarakat, kesejahteraan masyarakat dapat diwujudkan dengan pemenuhan dasar yaitu pendidikan dan kesehatan. Islam juga mengajarkan agar kita 
PENGARUH PERTUMBUHAN EKONOMI, REALISASI PENGELUARAN PENDIDIKAN, DAN REALISASI PENGELUARANKESEHATAN TERHADAP INDEKS PEMBANGUNAN MANUSIA DALAM PANDANGAN ISLAM DI PROVINSI SUMATERA UTARA

Zulaika Matondang selalu hidup sehat, karena orang yang sehat akan memiliki produktivitas yang tinggi, seperti yang termuat dalam Al-Qur'an surah Al-Muddatsir ayat 4 dan 5 yang berbunyi :

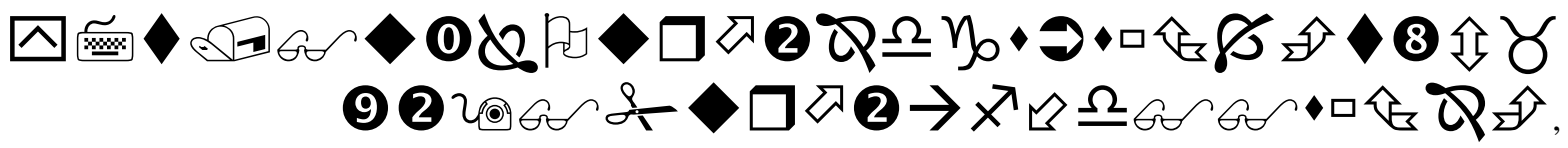

Artinya :

Dan pakaianmu bersihkanlah, dan perbuatan dosa tinggalkanlah

Untuk mewujudkan kesejahteraan masyarakat, pemerintah perlu melakukan investasi pada modal manusia sebagai indikator pembentuk indeks pembangunan manusia. Investasi pada modal manusiaberarti pengeluaran di bidang pelayanan kesehatan, pendidikan dan sosial pada umumnya, oleh karena itu pembentukan modal manusia bahkan dianggap lebih penting ketimbang pembentukan modal material (Jhingan, 2007). Perkembangan pengeluaran pemerintah untuk sektor pendidikan dan kesehatan dapat dilihat pada gambar berikut.

Gambar 3

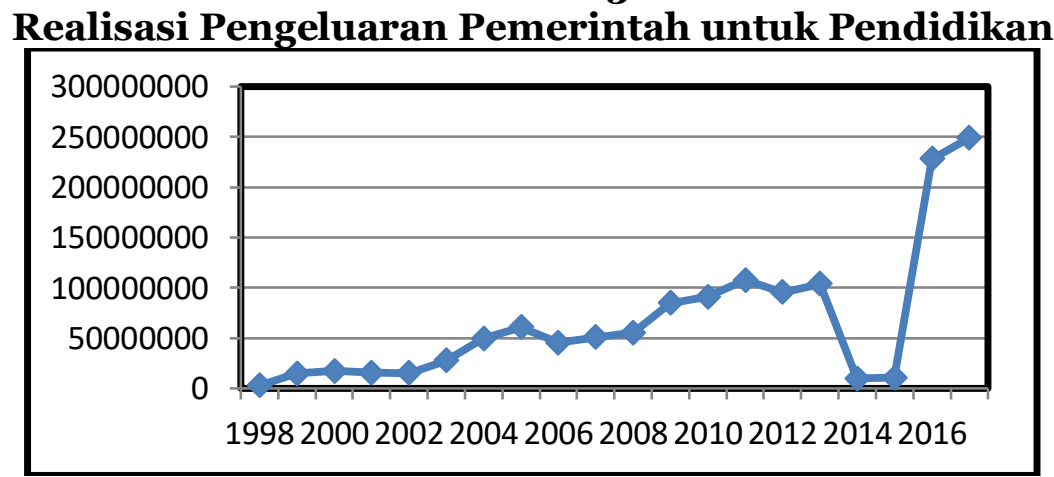

Gambar 4

Realisasi Pengeluaran Pemerintah untuk Kesehatan

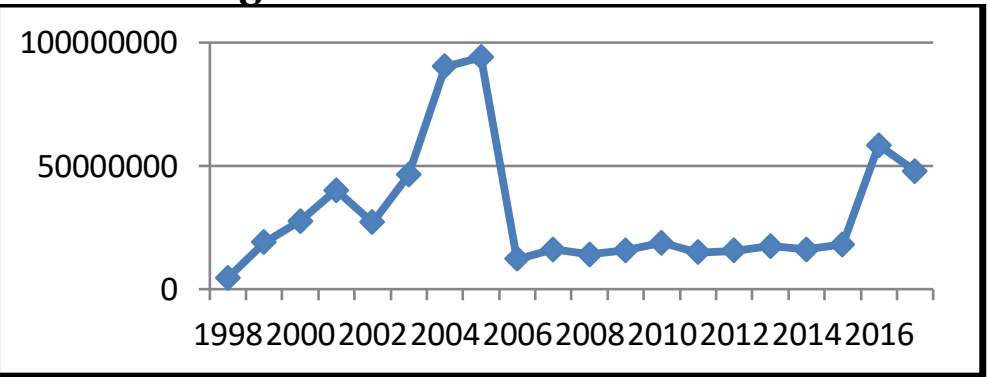

Pertumbuhan ekonomi yang baik menggambarkan produktivitas yang baik juga sehingga mempengaruhi indeks pembangunan manusia yang baik juga, akan tetapi yang ditunjukkan pada gambar 2 dan gambar 1, pada tahun 2007 sampai tahun 2009 pertumbuhan ekonomi mengalami penurunan akan tetapi indeks pembangunan manusia mengalami peningkatan, selain pertumbuhan ekonomi pengeluaran pendidikan dan kesehatan juga dapat mempengaruhi indeks pembangunan manusia, semakin banyak 
pengeluaran yang diberikan pemerintah dalam sektor pendidikan dan kesehatan diharapkan dapat meningkatkan indeks pembangunan manusianya, akan tetapi pada gambar 3 tahun 2000 sampai tahun 2001 menggambarkan realisasi pengeluaran pendidikan mengalami peningkatan akan tetapi indeks pembangunan manusianya mengalami penurunan dan begitu juga pada gambar 4 pada tahun 2000 sampai tahun 2001 dan tahun 2013 sampai tahun 2014 realisasi pengeluaran kesehatan mengalami peningkatan akan tetapi indeks pembangunan manusianya mengalami penurunan, kemudian tahun 2005 sampai tahun 2006 realisasi pengeluaran kesehatan mengalami penurunan akan tetapi indeks pembangunan manusianya mengalami peningkatan.Berdasarkan latar belakang yang telah dipaparkan, peneliti tertarik untuk mengangkat tema dengan judul "Pengaruh Pertumbuhan Ekonomi, Realisasi Pengeluaran Pendidikan, Dan Realisasi Pengeluaran Kesehatan Terhadap Indeks Pembangunan Manusia Dalam Pandangan Islam Di Provinsi Sumatera Utara".

Berdasarkan latar belakang tersebut, ada beberapa masalah yang akan dikaji dan diteliti yaitu apakah pertumbuhan ekonomi, realisasi pengeluaran pendidikan dan realisasi pengeluaran kesehatan berpengaruh terhadap indeks pembangunan manusia di provinsi Sumatera Utara baik secara parsial maupun secara simultan. Tujuan dari penelitian ini adalah untuk mengetahui sebesar apa tingkat pengaruh pertumbuhan ekonomi terhadap indeks pembangunan manusia, realisasi pengeluaran pendidikan terhadap indeks pembangunan manusia, realisasi pengeluaran kesehatan terhadap indeks pembangunan manusia di provinsi Sumatera Utara.

\section{TINJAUAN TEORITIK}

\section{Indeks Pembangunan Manusia}

Modal manusia yang dibahas dalam tinjauan teoritik penelitian ini adalah indeks pembangunan manusia atau Human Development Index merupakan pengkuruan perbandingan dari harapan hidup, melek huruf, pendidikan dan standar hidup untuk semua negara di seluruh dunia, dimana indeks pembangunan manusia dipengaruhi oleh beberapa faktor, diantaranya adalah pendidikan, kesehatan dan pertumbuhan ekonomi.

Pembentukan modal manusia merupakan proses memperoleh dan meningkatkan jumlah orang yang mempunyai keahlian, pendidikan dan pengalaman yang menentukan bagi pembangunan ekonomi dan politik suatu negara (Jhingan, 2007). (Schultz dalam Jhingan, 2007) mengemukakan ada lima cara pengembangan sumber daya manusia yang pertama adalah fasilitas dan pelayanan kesehatan, pada umumnya diartikan mencakup semua pengeluaran yang mempengaruhi harapan hidup, kekuatan dan stamina, tenaga serta vitalitas rakyat. Kedua adalah latihan jabatan, termasuk magang model lama yang diorganisasikan oleh perusahaan. Ketiga adalah pendidikan yang diorganisasikan secara formal pada tingkat dasar, menengah dan tinggi. Keempat adalah program studi bagi orang 


\section{PENGARUH PERTUMBUHAN EKONOMI, REALISASI PENGELUARAN PENDIDIKAN, DAN REALISASI PENGELUARANKESEHATAN TERHADAP INDEKS PEMBANGUNAN MANUSIA DALAM PANDANGAN ISLAM DI PROVINSI SUMATERA UTARA}

Zulaika Matondang dewasa yang tidak diorganisasikan oleh perusahaan, termasuk program ekstension khususnya pada pertanian. Dan kelima adalah migrasi perorangan dan keluarga untuk menyesuaikan ciri dengan kesempatan kerja yang selalu berubah. Berdasarkan kelima hal tersebut maka dapat dinyatakan bahwa laju akumulasi modal manusia harus melebihi tidak hanya laju pertumbuhan tenaga buruh tetapi juga laju pertumbuhan ekonomi.

Pendidikan memainkan peran utama dalam membentuk kemampuan sebuah negara berkembang untuk menyerap teknologi modern dan untuk mengembangkan kapasitas agar tercipta pertumbuhan serta pembangunan yang berkelanjutan, dan kesehatan merupakan prasyarat bagi peningkatan produktivitas, sementara keberhasilan pendidikan juga bertumpu pada kesehatan yang baik. Keterkaitan antara kesehatan dan pendidikan mencakup perlakuan analitis yang serupa, karena keduanya merupakan bentuk dari modal manusia yang sangat erat kaitannya dengan pembangunan ekonomi (Todaro, 2006). Oleh karena itulah WHO (World Health Organization) menyimpulkan dalam World Health Report tahun 2000 tentag sistem kesehatan bahwa tanggung jawab utama atas kinerja sistem kesehatan suatu negara terletak di pundak pemerintah. Dengan pernyataan ini, pejabat yang bijaksana akan mengambil pelajaran dari berbagai studi yang menunjukkan kaitan antara pendidikan dan kesehatan dengan mengeluarkan anggaran dana untuk sektor pendidikan dan kesehatan.

\section{Pertumbuhan Ekonomi}

Pertumbuhan ekonomi merupakan kenaikan pendapatan nasional secara berarti (dengan meningkatnya pendapatan perkapita) dalam suatu periode perhitungan tertentu (Putong dan Andjaswati, 2008). Angka pertumbuhan ekonomi umumnya dalam bentuk persentase, bisa bertanda positif maupun negatif. Negatifnya pertumbuhan ekonomi bisa saja disebabkan adanya penurunan yang lebih besar dari pendapatan nasional. Pertumbuhan ekonomi dapat juga digunakan untuk mengukur prestasi dari perkembangan suatu ekonomi, dalam kegiatan perekonomian, pertumbuhan ekonomi berarti perkembangan fiskal produksi barang dan jasa yang berlaku di suatu negara, seperti pertambahan dan jumlah produksi barang industri, perkembangan infrastruktur, pertambahan jumlah sekolah, pertambahan produksi sektor jasa dan pertambahan produksi barang modal (Sukirno, 2010). Ada beberapa faktor yang menentukan pertumbuhan ekonomi yaitu tanah dan kekayaan alam lainnya, jumlah dan mutu dari penduduk dan tenaga kerja, barang-barang modal dan tingkat teknologi serta sistem sosial dan sikap masyarakat.

\section{Realisasi Pengeluaran Pendidikan dan Kesehatan}

Belanja yang dilakukan pemerintah untuk pendidikan dan kesehatan diatur dalam Undang-Undang Republik Indonesia Nomor 14 Tahun 2015 tentang Anggaran Pendapatan dan belanja Negara. Pemerintah berperan penting dalam upaya pengembangan sumber daya manusia melalui pendidikan, karena pendidikan merupakan barang publik atau sebagai hakhak sosial yang dijamin oleh pemerintah, hal ini sesuai dengan UUD 1945 pasal 31 ayat 2, 3 
dan 4 yang menyatakan bahwa setiap warga negara berhak mendapat pendidikan, pemerintah mewajibkan setiap warga negara untuk mengikuti pendidikan dasar dan wajib membiayainya serta pemerintah minimal mengalokasikan dana pendidikan sebesar 20 persen dari APBN dan APBD, hal ini juga dikuatkan dengan keputusan Mahkamah Konstitusi Nomor 013/PUU-VI/2008 (Ashari, 2014).

Alokasi anggaran pendidikan lebih spesifik dituangkan dalam pasal 49 UU Nomor 20 Tahun 2003 pasal 1 yaitu dana pendidikan selain gaji pendidik dan biaya pendidikan kedinasan dialokasikan minimal 20 persen dari Anggaran Pendapatan Belanja Negara (APBN) pada sektor pendidikan dan minimal 20 persen dari Anggaran Pendapatan Belanja Daerah (APBD). Hal ini juga didukung oleh adanya Peraturan Pemerintah Republik Indonesia Nomor 48 Tahun 2008 tentang Pendanaan Pendidikan.

Alokasi dana kesehatan juga termuat dalam Undang-Undang Nomor 36 tahun 2009 tentang Kesehatan, dalam Undang-Undang tersebut di dalam pasal 171 ayat 1 dan 2, dimana besar anggaran kesehatan pemerintah dialokasikan minimal sebesar 5 persen dari Anggaran Pendapatan dan Belanja Negara di luar gaji dan besar anggaran kesehatan pemerintah daerah provinsi, kabupaten/kota dialokasikan minimal 10 persen dari Anggaran Pendapatan dan Belanja Daerah di luar gaji.

\section{Hipotesis}

Menurut (Noor, 2015), hipotesis merupakan jawaban sementara atau masih bersifat dugaan terhadap pertanyaan yang diajukan sebelumnya dan merupakan kesimpulan dari kerangka berpikir. Hipotesis yang baik harus sesuai dengan tema yang diteliti, harus konsisten dengan logika, dinyatakan secara ringkas dan dapat diuji. Berdasarkan rumusan masalah, maka hipotesis penelitian ini adalah :

$\mathrm{H}_{1} \quad=$ Terdapat pengaruh pertumbuhan ekonomi terhadap indeks pembangunan manusia di provinsi Sumatera Utara.

$\mathrm{H}_{2} \quad=$ Terdapat pengaruh realisasi pengeluaran pendidikan terhadap indeks pembangunan manusia di provinsi Sumatera Utara.

$\mathrm{H}_{3} \quad=$ Terdapat pengaruh realisasi pengeluaran kesehatan terhadap indeks pembangunan manusia di provinsi Sumatera Utara.

$\mathrm{H}_{4} \quad=$ Terdapat pengaruh pertumbuhan ekonomi, realisasi pengeluaran pendidikan dan realisasi pengeluaran kesehatan terhadap indeks pembangunan manusia di provinsi Sumatera Utara.

\section{METODE PENELITIAN}

Analisis data yang digunakan dalam penelitian ini agar sesuai dengan tujuan penelitian, guna mengetahui pengaruh pertumbuhan ekonomi, realisasi pengeluaran pendidikan dan realisasi pengeluaran kesehatan terhadap indeks pembangunan manusia di provinsi Sumatera Utara yaitu dengan menggunakan rumus regresi linier berganda. Menurut 


\section{PENGARUH PERTUMBUHAN EKONOMI, REALISASI PENGELUARAN PENDIDIKAN, DAN REALISASI PENGELUARANKESEHATAN TERHADAP INDEKS PEMBANGUNAN MANUSIA DALAM PANDANGAN ISLAM DI PROVINSI SUMATERA UTARA}

Zulaika Matondang (Gulo : 2010), jika variabel independen yang berhubungan dengan satu variabel dependen, maka analisis regresi tersebut disebut regresi linier berganda. Persamaan regresi linier berganda yang digunakan dalam penelitian ini adalah :

$$
\operatorname{LnIPM}=\mathrm{a}+\mathrm{b}_{1} \operatorname{LnPE}+\mathrm{b}_{2} \operatorname{LnRPP}+\mathrm{b}_{3} \operatorname{LnRPK}
$$

IPM = Indeks Pembangunan Manusia

a $\quad=$ Konstanta

$\mathrm{b}_{1}, \mathrm{~b}_{2}, \mathrm{~b}_{3} \quad=$ Koefisien

$\mathrm{PE} \quad=$ Pertumbuhan Ekonomi

RPP $\quad=$ Realisasi Pengeluaran Pendidikan

RPK = Realisasi Pengeluaran Kesehatan

\section{Pengujian Asumsi Klasik}

Uji asumsi klasik digunakan untuk menguji normalitas data penelitian, uji multokilinearitas, uji heteroskedastisitas dan uji autokorelasi. Menurut (Sugiono dan Susanto, 2015), uji normalitas bertujuan untuk menguji data penelitian baik variabel dependen maupun variabel independen terdistribusi normal atau tidak dengan menggunakan kolmogrov-smirnow pada taraf signifikan 0,05. Dan uji multikolinieritas digunakan untuk melihat adanya hubungan linier sempurna diantara variabel independennya dengan melihat nilai VIF (Variance Inflasion Factor). Dan uji heteroskedastisitas digunakan untuk mengetahui ada atau tidaknya penyimpangan asumsi klasik melalui penyebaran titik yang tidak membentuk pola. Dan mengukur uji autokorelasi dengan melihat hasil uji Durbin-Watson (DW).

\section{Pengujian Hipotesis}

Uji hipotesis digunakan untuk mengukur besarnya pengaruh variabel independen terhadap variabel dependen. Untuk mengukur seberapa jauh kemampuan model dalam menerangkan variasi dependen digunakan uji koefisien determinasi $\left(\mathrm{R}^{2}\right)$, menurut (Setiawan dan Kusrini, 2010), nilai yang mendekati satu berarti variabel-variabel independen memberikan hampir semua informasi yang dibutuhkan untuk memprediksi variasi variabel dependen. Untuk mengetahui apakah ada model regresi variabel independen secara parsial berpengaruh signifikan terhadap variabel dependen, maka digunakanlah uji $t$, menurut (Siregar, 2014), kaidah pengujian untuk menguji secara parsial yaitu jika $\mathrm{T}_{\text {hitung }} \leq \mathrm{T}_{\text {tabel }}$ maka $\mathrm{H}_{\mathrm{o}}$ diterima dan $\mathrm{H}_{\mathrm{a}}$ ditolak, dan jika $\mathrm{T}_{\text {hitung }} \geq \mathrm{T}_{\text {tabel }}$ maka $\mathrm{H}_{\mathrm{o}}$ ditolak dan $\mathrm{H}_{\mathrm{a}}$ diterima. Dan untuk mengetahui pengaruh semua variabel independen terhadap variabel dependen maka digunakanlah uji $\mathrm{F}$, uji ini dilakukan dengan syarat bila $\mathrm{F}_{\text {hitung }}<\mathrm{F}_{\text {tabel }}$ maka $\mathrm{H}_{\mathrm{o}}$ diterima dan $\mathrm{H}_{\mathrm{a}}$ ditolak, bila $\mathrm{F}_{\text {hitung }}>\mathrm{F}_{\text {tabel }}$ maka $\mathrm{H}_{\mathrm{o}}$ ditolak dan $\mathrm{H}_{\mathrm{a}}$ diterima.

\section{HASIL DAN PEMBAHASAN}


Populasi yang digunakan dalam penelitian ini adalah provinsi Sumatera Utara dengan data yang diteliti adalah nilai dari indeks pembangunan manusia, realisasi pengeluaran pendidikan, realisasi pengeluaran kesehatan dan pertumbuhan ekonomi dari tahun 1998 sampai tahun 2017 dengan jumlah populasi sebanyak 20 tahun. Sampel merupakan suatu bagian dari populasi yang mencakup sejumlah anggota yang dipilih dari populasi. Teknik pengambilan sampel dalam penelitian ini adalah total sampling. Total sampling ini dipilih jika populasi dianggap kecil atau kurang dari 100 (Noor, 2015).

Sebelum melakukan analisis data, terlebih dahulu menentukan uji normalitas dari data penelitian, adapun hasil uji normalitas penelitian ini adalah :

Tabel 1

Hasil Uji Normalitas One-Sample Kolmogorov-Smirnov Test

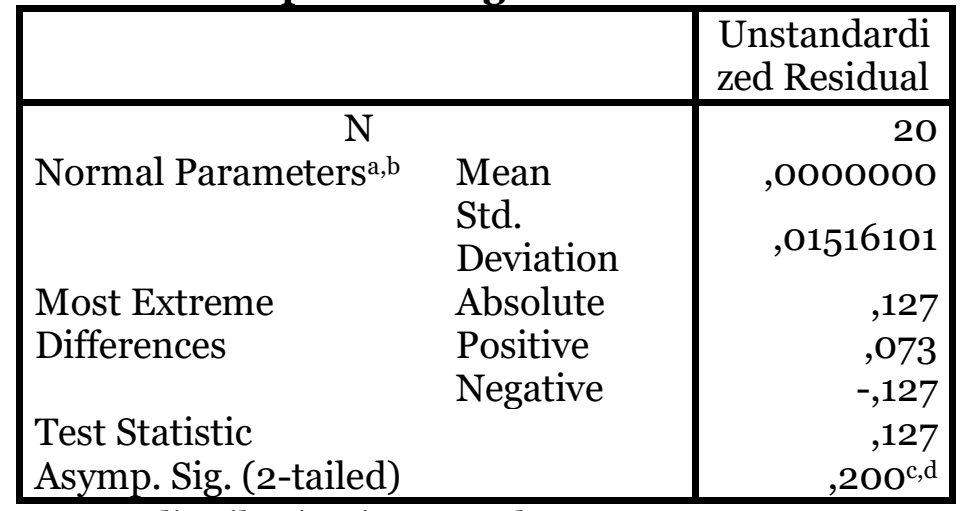

a. Test distribution is Normal.

b. Calculated from data.

c. Lilliefors Significance Correction.

$\mathrm{d}$. This is a lower bound of the true significance.

Dari hasil uji di atas, dapat kita lihat nilai dari Asymp. Sig. (2-tailed) sebesar 0,200 yang nilainya diatas dari 0,05 , apabila hasil perhitungan kolmogrov-smirnow diatas dari 0,05 maka data terdistribusi normal. Sehingga data dalam penelitian ini terdistribusi normal. Jika data sudah normal maka berikutnya adalah menguji multikolinieritas, adapun hasil ujinya adalah :

Tabel 2 Hasil Uji Multikolinearitas

\begin{tabular}{|ll|r|r|}
\hline \multirow{2}{*}{ Model } & \multicolumn{2}{|c|}{ Collinearity Statistics } \\
\cline { 3 - 4 } & Tolerance & \multicolumn{1}{c|}{ VIF } \\
\hline 1 & (Constant) & & \\
& PE &, 522 & 1,915 \\
& RPP &, 453 & 2,206 \\
& RPK &, 824 & 1,214 \\
\hline
\end{tabular}

Dari hasil uji multikolinieritas di atas, nilai VIF berada di bawah 5, jika nilai VIF berada di bawah 5 maka tiap-tiap variabel independen dalam penelitian ini yaitu 
PENGARUH PERTUMBUHAN EKONOMI, REALISASI PENGELUARAN PENDIDIKAN, DAN REALISASI PENGELUARANKESEHATAN TERHADAP INDEKS PEMBANGUNAN MANUSIA DALAM PANDANGAN ISLAM DI PROVINSI SUMATERA UTARA

Zulaika Matondang pertumbuhan ekonomi, realisasi pengeluaran pendidikan dan realisasi pengeluaran kesehatan terbebas dari masalah multikolinieritas. Uji asumsi klasik berikutnya adalah uji heteroskedastisitas yaitu :

\section{Gambar 5}

Hasil Uji Heteroskedastisitas

Scatterplot

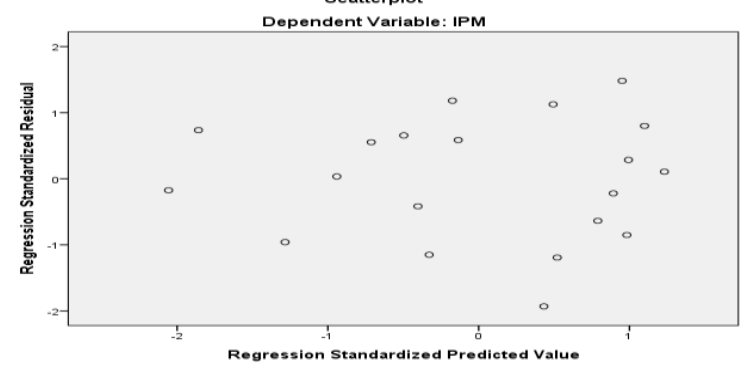

Suatu regresi dikatakan terdeteksi heteroskedastisitasnya apabila diagram pencar residual membentuk pola tertentu, dan berdasarkan gambar diatas dapat dilihat bahwa diagram pencar residual tidak membentuk pola tertentu, sehingga disimpulkan bahwa regresi dalam penelitian ini terbebas dari kasus heteroskedastisitas. Dan uji asumsi berikutnya adalah uji autokorelasi yang ditunjukkan dari hasil berikut :

Tabel 3

Hasil Uji Autokorelasi

\begin{tabular}{|l|c|r|r|r|}
\hline Model & $\mathrm{R}$ & R Square & $\begin{array}{c}\text { Adjusted R } \\
\text { Square }\end{array}$ & $\begin{array}{l}\text { Durbin- } \\
\text { Watson }\end{array}$ \\
\hline 1 &, $930^{\mathrm{a}}$ &, 865 &, 840 & 1,414 \\
\hline
\end{tabular}

Hasil uji autokorelasi dianalisis dengan melihat nilai Durbin-Watson (DW), nilai DW dari tabel di atas adalah 1,414, dari hasil tersebut tidak terjadi autokorelasi karena nilai DW lebih besar dari -2 dan lebih kecil dari +2 $(-2<1,654<+2)$.

Untuk mengetahui pengaruh pertumbuhan ekonomi, realisasi pengeluaran pendidikan, realisasi pengeluaran kesehatan terhadap indeks pembangunan manusia di provinsi Sumatera Utara digunakan program SPSS (Statistical Product Solution Service) versi 22, dengan persamaan regresi yang terbentuk :

Tabel 4

Analisis Regresi Linier Berganda

\begin{tabular}{|ll|r|r|r|}
\hline \multirow{2}{*}{ Model } & \multicolumn{2}{|c|}{$\begin{array}{c}\text { Unstandardized } \\
\text { Coefficients }\end{array}$} & $\begin{array}{c}\text { Standardized } \\
\text { Coefficients }\end{array}$ \\
\cline { 2 - 5 } & (Constant) & \multicolumn{1}{|c|}{ B } & Std. Error & \multicolumn{1}{c|}{ Beta } \\
\hline 1 & 4,102 &, 092 & \\
& PE &, 088 &, 018 &, 610 \\
& RPP &, 016 &, 005 &, 442 \\
& RPK &,- 015 &, 006 &,- 271 \\
\hline
\end{tabular}

$\mathrm{IPM}=4,102+0,088 \mathrm{PE}+0,016 \mathrm{RPP}-0,015 \mathrm{RPK}$ 
Untuk mengetahui seberapa besar pengaruh variabel independen terhadap variabel dependennya, dapat dilihat pada tabel berikut :

Tabel 5

\section{Hasil Uji Determinasi $\mathbf{R}^{2}$}

\begin{tabular}{|l|c|r|r|r|}
\hline Model & R & R Square & $\begin{array}{c}\text { Adjusted R } \\
\text { Square }\end{array}$ & $\begin{array}{c}\text { Std. Error of } \\
\text { the Estimate }\end{array}$ \\
\hline 1 &, $930^{\mathrm{a}}$ &, 865 &, 840 &, 016521324 \\
\hline
\end{tabular}

Dari tabel diatas dapat diketahui bahwa nilai $R$ Squarenya sebesar 0,865 , artinya sebesar 86,5 persen variabel pertumbuhan ekonomi, realisasi pengeluaran pendidikan dan realisasi pengeluaran kesehatan terhadap indeks pembangunan manusia di provinsi Sumatera Utara. Sedangkan sisanya sebesar 13,5 persen dipengaruhi oleh variabel lain diluar dari penelitian ini.

\section{Pembuktian Hipotesis}

Uji hipotesis dalam penelitian ini terdiri dari uji T dan uji F. Uji parsial dengan T-test digunakan untuk mengetahui apakah secara parsial pertumbuhan ekonomi, realisasi pengeluaran pendidikan dan realisasi pengeluaran kesehatan memiliki pengaruh atau tidak terhadap indeks pembangunan manusia. Pengujian yang dilakukan dengan melihat nilai t hitung yang dibandingkan dengan nilai t tabel dengan nilai t tabel sebesar 2,119. Adapun hasil dari t hitung adalah :

Tabel 6

Hasil uji t

\begin{tabular}{|c|c|c|c|c|c|c|}
\hline \multirow{2}{*}{\multicolumn{2}{|c|}{ Model }} & \multicolumn{2}{|c|}{$\begin{array}{c}\text { Unstandardized } \\
\text { Coefficients }\end{array}$} & \multirow{2}{*}{$\begin{array}{c}\begin{array}{c}\text { Standardized } \\
\text { Coefficients }\end{array} \\
\text { Beta }\end{array}$} & \multirow[b]{2}{*}{$\mathrm{t}$} & \multirow[b]{2}{*}{ Sig. } \\
\hline & & $\mathrm{B}$ & Std. Error & & & \\
\hline \multirow[t]{4}{*}{1} & (Constant) & 4,102 & ,092 & & 44,623 & , OOO \\
\hline & $\mathrm{PE}$ & , o88 & , 018 & ,610 & 4,793 & , OOO \\
\hline & RPP & ,016 & ,005 & , 442 & 3,239 & ,005 \\
\hline & RPK &,- 015 & ,006 &,- 271 & $-2,678$ & ,017 \\
\hline
\end{tabular}

\section{Pengaruh Pertumbuhan Ekonomi Terhadap Indeks Pembangunan Manusia di} Provinsi Sumatera Utara

Pembangunan manusia sangat penting dalam perekonomian, karena manusia yang dalam hal ini adalah penduduk yang akan menjalankan dan sebagai penggerak perekonomian suatu wilayah, inilah dasar bahwa pertumbuhan ekonomi dapat mempengaruhi indeks pembangunan manusia. Hal ini didasari dari teori Kuznet yang menyatakan bahwa salah satu karakteristik pertumbuhan ekonomi modern adalah tingginya pertumbuhan output per kapita (Todaro, 2006). Pertumbuhan output disini adalah pendapatan per kapita, artinya semakin tinggi pertumbuhan ekonomi menunjukkan bahwa pendapatan per kapitanya juga meningkat, sehingga pola konsumsi berubah dan terjadilah 
PENGARUH PERTUMBUHAN EKONOMI, REALISASI PENGELUARAN

PENDIDIKAN, DAN REALISASI PENGELUARANKESEHATAN

TERHADAP INDEKS PEMBANGUNAN MANUSIA DALAM

PANDANGAN ISLAM DI PROVINSI SUMATERA UTARA

Zulaika Matondang

peningkatan daya beli masyarakat yang akan meningkatkan indeks pembangunan manusia, karena daya beli masyarakat merupakan salah satu indikator dalam indeks pembangunan manusia yaitu indikator pendapatan.

Untuk variabel pertumbuhan ekonomi, nilai t hitungnya sebesar 4,793 dengan nilai t tabel sebesar 2,119, artinya untuk variabel pertumbuhan ekonomi t hitungnya lebih besar daripada nilai t tabelnya yaitu 4,793 $>2,119$ artinya pertumbuhan ekonomi secara parsial berpengaruh terhadap indeks pembangunan manusia di provinsi Sumatera Utara. Penelitian ini sejalan dengan hasil penelitian yang dilakukan oleh Denni Sulistio Mirza dan Anggatia Ariza yang menyatakan bahwa pertumbuhan ekonomi berpengaruh terhadap indeks pembangunan manusia.

Pengaruh Realisasi Pengeluaran Pendidikan Terhadap Indeks Pembangunan Manusia di Provinsi Sumatera Utara

Pendidikan dan kesehatan merupakan modal dasar yang harus dimiliki masyarakatnya untuk melihat indeks pembangunan manusianya. Modal manusia melalui pendidikan akan dapat menambah produktivitas penduduk, dengan produktivitas yang tinggi akan meningkatkan pendapatan per kapita suatu wilayah yang justru akan meningkatkan pertumbuhan ekonomi di wilayah tersebut. Pendidikan sangat penting dimiliki setiap insan di dalam tiap negara, seperti halnya di Indonesia, sektor pendidikan sangat didukung dengan dana yang telah dianggarkan minimal 20 persen dari APBN dan 20 persen dari APBD dan bahkan sektor pendidikan ini diatur dalam UUD 1945. Anggaran yang dikeluarkan untuk pendidikan harus tepat sasaran dan harus seoptimal mungkin, guna meningkatkan kualitas masyarakat dan generasi penerus bangsa sehingga berdampak pada peningkatan indeks pembangunan manusianya.

Untuk variabel realisasi pengeluaran pendidikan, nilai t hitungnya sebesar 3,239 dengan nilai t tabel sebesar 2,119, artinya untuk variabel realisasi pengeluaran pendidikan $t$ hitungnya lebih besar daripada nilai t tabelnya yaitu 3,239 $>2,119$ artinya realisasi pengeluaran pendidikan secara parsial berpengaruh terhadap indeks pembangunan manusia di provinsi Sumatera Utara. Penelitian ini sejalan dengan hasil penelitian yang dilakukan oleh Syahril ilhami dan Agnes Marida Tindaon yang menyatakan bahwa realisasi pengeluaran pendidikan berpengaruh terhadap indeks pembangunan manusia.

Pengaruh Realisasi Pengeluaran Kesehatan Terhadap Indeks Pembangunan Manusia di Provinsi Sumatera Utara

Kesehatan merupakan tujuan pembangunan yang mendasar, dimana kesehatan merupakan inti dari kesejahteraan, besar anggaran kesehatan pemerintah dialokasikan minimal sebesar 5 persen dari Anggaran Pendapatan dan Belanja Negara dan besar anggaran kesehatan pemerintah daerah provinsi, kabupaten/kota dialokasikan minimal 10 persen dari Anggaran Pendapatan dan Belanja Daerah. Hal inilah yang mendasari bahwa dana yang 
dikeluarkan pemerintah untuk kesehatan diharapkan dapat meningkatkan kualitas manusianya sehingga dapat meningkatkan indeks pembangunan manusianya.

Untuk variabel realisasi pengeluaran kesehatan, nilai -t hitungnya sebesar -2,678 dengan nilai -t tabel sebesar -2,119, artinya untuk variabel realisasi pengeluaran pendidikan $\mathrm{t}$ hitungnya lebih kecil daripada nilai $t$ tabelnya yaitu -2,678 <-2,119 artinya realisasi pengeluaran kesehatan secara parsial berpengaruh terhadap indeks pembangunan manusia di provinsi Sumatera Utara. Penelitian ini sejalan dengan hasil penelitian yang dilakukan oleh Agus Tri Basuki dan Endah Saptutyningsih, Agnes Marida Tindaon dan Nadia Ayu Bhakti yang menyatakan bahwa realisasi pengeluaran kesehatan berpengaruh terhadap indeks pembangunan manusia.

\section{Pengaruh Pertumbuhan Ekonomi, Realisasi Pengeluaran Pendidikan dan Realisasi Pengeluaran Kesehatan Terhadap Indeks Pembangunan Manusia di Provinsi Sumatera Utara}

Uji simultan atau uji $\mathrm{F}$ bertujuan untuk mengetahui pengaruh variabel independen secara bersama-sama berpengaruhkah atau tidak terhadap variabel dependennya dengan membandingkan antara nilai $\mathrm{F}$ hitung dan $\mathrm{F}$ tabel, dimana nilai $\mathrm{F}$ tabelnya adalah 3,10, hasil uji F nya ditunjukkan pada tabel berikut :

Tabel 7

Hasil Uji F

\begin{tabular}{|c|c|c|c|c|c|c|}
\hline \multicolumn{7}{|c|}{ ANOVA $^{a}$} \\
\hline \multicolumn{2}{|c|}{ Model } & $\begin{array}{l}\text { Sum of } \\
\text { Squares }\end{array}$ & Df & $\begin{array}{c}\text { Mean } \\
\text { Square }\end{array}$ & $F$ & Sig. \\
\hline \multirow[t]{3}{*}{1} & Regression & ,028 & 3 & \multirow{3}{*}{$\begin{array}{l}\text {,009 } \\
\text {,000 }\end{array}$} & \multirow[t]{3}{*}{34,130} & \multirow[t]{3}{*}{, $\mathrm{OOO}^{\mathrm{b}}$} \\
\hline & Residual & ,004 & 16 & & & \\
\hline & Total & ,032 & 19 & & & \\
\hline
\end{tabular}

a. Dependent Variable: IPM

b. Predictors: (Constant), RPK, PE, RPP

Berdasarkan tabel diatas, nilai F hitung sebesar 34,130 dan nilai ini lebih besar dari nilai $\mathrm{F}$ tabel yaitu sebesar 3,10, artinya nilai $\mathrm{F}$ hitung lebih besar daripada nilai $\mathrm{F}$ tabel yaitu 34,130 > 3,10. Jika nilai $\mathrm{F}$ hitung lebih besar daripada nilai $\mathrm{F}$ tabel maka diartikan bahwa pertumbuhan ekonomi, realisasi pengeluaran pendidikan dan realisasi pengeluaran kesehatan berpengaruh terhadap indeks pembangunan manusia di provinsi Sumatera Utara.

\section{KESIMPULAN}




\section{PENGARUH PERTUMBUHAN EKONOMI, REALISASI PENGELUARAN PENDIDIKAN, DAN REALISASI PENGELUARANKESEHATAN TERHADAP INDEKS PEMBANGUNAN MANUSIA DALAM PANDANGAN ISLAM DI PROVINSI SUMATERA UTARA}

Hasil penelitian diperoleh persamaan IPM = 4,102 + 0,088 PE + 0,016 RPP - 0,015 RPKdapat dijelaskan bahwa jika seluruh variabel independen dianggap konstan atau o, maka indeks pembangunan manusia di provinsi Sumatera Utara sebesar 4,102. Dan jika pertumbuhan ekonomi naik sebesar 1 satuan maka indeks pembangunan manusia di provinsi Sumatera Utara naik sebesar o,o88, dan jika realisasi pengeluaran pendidikan naik sebesar 1 satuan maka indeks pembangunan manusia di provinsi Sumatera Utara naik sebesar o,016, dan jika realisasi pengeluaran kesehatan naik sebesar 1 satuan maka indeks pembangunan manusia di provinsi Sumatera Utara turun sebesar 0,015. Pertumbuhan ekonomi berpengaruh terhadap indeks pembangunan manusia dengan pembuktian hasil $\mathrm{t}$ hitung lebih besar nilainya daripada t tabel yaitu 4,793 > 2,119 artinya pertumbuhan ekonomi secara parsial berpengaruh terhadap indeks pembangunan manusia di provinsi Sumatera Utara.

Realisasi pengeluaran pendidikan berpengaruh terhadap indeks pembangunan manusia dengan pembuktian hasil t hitung lebih besar nilainya daripada $t$ tabel yaitu 3,239 > 2,119 artinya realisasi pengeluaran pendidikan secara parsial berpengaruh terhadap indeks pembangunan manusia di provinsi Sumatera Utara.

Realisasi pengeluaran kesehatan berpengaruh terhadap indeks pembangunan manusia dengan pembuktian hasil -t hitung lebih kecil nilainya daripada -t tabel yaitu -2,678 $<-2,119$ artinya realisasi pengeluaran pendidikan secara parsial berpengaruh terhadap indeks pembangunan manusia di provinsi Sumatera Utara.

Pertumbuhan ekonomi, realisasi pengeluaran pendidikan dan realisasi pengeluaran kesehatan berpengaruh terhadap indeks pembangunan manusia di provinsi Sumatera Utara dengan dibuktikan dari nilai F hitung lebih besar daripada F tabel yaitu 34,130 > 3,10.

\section{DAFTAR PUSTAKA}

Andaiyani. 2012. Pengaruh Indeks Pembangunan Manusia, Pertumbuhan Ekonomi, dan Belanja Operasional terhadap Jumlah Alokasi Belanja Modal pada Pemerintahan Kabupaten/Kota di Provinsi Kalimantan Barat. Ringkasan Thesis; Pontianak, Program Pascasarjana Universitas Tanjungpura

Ariza, Anggatia. Pengaruh Pertumbuhan Ekonomi dan Belanja Modal Terhadap Indeks Pembangunan Manusia (IPM) Dalam Perspektif Islam. Fakultas Syariah dan Ekonomi Islam IAIN Pontianak.

Ashari, Hasan. 2014. Anggaran Pendidikan 20\%, Apakah sudah dialokasikan?. Diakses melalui www.bppk.kemenkeu.go.id pada 30 Desember 2014 pukul 11 wib.

Basuki, Tri, Agus dan Saptutyningsih, Endah. Analisis Faktor-Faktor Yang Berpengaruh Terhadap Indeks Pembangunan Manusia Tahun 2008 - 2014 (Studi Kasus Kab/Kota D I Yogyakarta. 
Bhakti, Ayu, Nadia. 2014. Analisis Faktor-Faktor Yang Mempengaruhi Indeks Pembangunan Manusia di Indonesia Periode 2008 - 2012. Jurnal Ekuitas Volume 18 Nomor 4, Universitas Jenderal Soedirman.

Gulo, W. 2010. Metodologi Penelitian, Jakarta : PT. Gramedia Widiasarana Indonesia

Ilhami, Syahril. 2014. Analisis Pengaruh Anggaran Pendidikan Terhadap Indeks Pembangunan Manusia di Indonesia. Tesis Institut Pertanian Bogor.

Jhingan, M.L. 2007. Ekonomi Pembangunan dan Perencanaan. Jakarta : PT. Raja Grafindo Persada.

Mirza, Sulistio, Denni. 2011. Pengaruh Kemiskinan, Pertumbuhan Ekonomi dan Belanja Modal Terhadap IPM Jawa Tengah. Fakultas Ekonomi Universitas Negeri Semarang, Jejak Volume 4 Nomor 2.

Noor, Juliansyah. 2015. Metodologi Penelitian, Jakarta : Penerbit Kencana.

Putong, Iskandar dan Andjaswati, ND. 2008. Pengantar Ekonomi Makro, Jakarta : Mitra Wacana Media.

Setiawan dan Kusrini, Endah, Dwi. 2010. Ekonometrika, Yogyakarta : Andi.

Setiawan, Bhakti, Mohammad dan Hakim, Abdul. Indeks Pembangunan Manusia Indonesia. Universitas Islam Indonesia

Siregar, Syofian. 2014. Statistik Parametrik untuk Penelitian Kuantitatif, Jakarta : Bumi Aksara.

Sugiono dan Susanto, Agus. 2015. Cara Mudah Belajar SPSS dan Lisrel Teori Dan Aplikasi Untuk Analisis Data Penelitian, Bandung : Alfabeta.

Sukirno, Sadono. 2010. Makroekonomi (Teori Pengantar Edisi Ketiga), Jakarta : PT. Rajawali Pers.

Tindaon, Marida, Agnes. 2016. Analisis Faktor-Faktor Yang Mempengaruhi Indeks Pembangunan Manusia Pada Kabupaten/Kota di Provinsi Sumatera Utara. Universitas Sumatera Utara.

Todaro, P, Michael dan Smith, C, Stephen. 2006. Pembangunan Ekonomi Edisi Kesembilan Jilid 1, Jakarta : Penerbit Erlangga. 